\title{
Investigation of the molecular epidemiology of Acinetobacter baumannii isolated from patients and environmental contamination
}

\author{
Chunmei Ying ${ }^{1,3}$, Yongli $\mathrm{Li}^{1,3}$, Yaping Wang ${ }^{1}$, Bing Zheng ${ }^{1}$ and Chengde Yang ${ }^{2}$
}

The objective of this work was to investigate correlations between Acinetobacter baumannii isolates from neurosurgical intensive care unit patients and its environment. This is a prospective, observational study. The minimal inhibitory concentrations of antimicrobial agents against 27 clinical and 28 environmental isolates were determined by the agar dilution method. Molecular genotyping was performed by enterobacterial repetitive intergenic consensus PCR (ERIC-PCR), pulsed-field gel electrophoresis (PFGE) and multi-locus sequence typing (MLST). The presence of carbapenemase and metallo- $\beta$-lactamase genes were analyzed by specific PCRs and DNA sequencing. From the clinical $A$. baumannii isolates, $25.9 \%$ were found resistant to minocycline, $51.9 \%$ to cefoperazone-sulbactam, $59.3 \%$ to imipenem and $70 \%$ resistant to other antimicrobial agents. Environmental isolates were more sensitive compared with clinical isolates $(P<0.05)$. Twenty-seven clinical isolates comprised three ERIC-PCR genotypes, four major PFGE pulsotypes and five distinct MLST sequence types (STs) (ST208, ST368, ST191, ST195, ST540), all belonging to CC92 with only one locus (gpi) difference among them. Twenty-eight environmental isolates showed more diverse genetic types than clinical isolates and comprised six ERIC-PCR groups, nine PFGE groups and two main STs (ST208, ST229). Four clinical and 15 environmental isolates could not be identified by MLST and were assigned to non-clonal STs. We identified the presence of the bla $a_{0 A-23}$ carbapenemase encoding gene in most of the clinical (21/27) but fewer in the environmental isolates (3/28). The $A$. baumannii strains isolated from patients were genetically similar to the environmental strains, with CC92 members as the major fraction but with different antibiotic susceptibilities.

The Journal of Antibiotics (2015) 68, 562-567; doi:10.1038/ja.2015.30; published online 15 April 2015

\section{INTRODUCTION}

The Gram-negative bacterium Acinetobacter baumannii is one of the critical pathogens of hospital-acquired infections, including pneumonia, especially ventilator-associated pneumonia, meningitis, bacteremia, urinary tract infections, surgical wounds, as well as soft tissue infections. ${ }^{1}$ A. baumannii possesses an uncanny ability to survive in both moist and dry conditions for many weeks or even months, hence this organism is widely distributed in natural and nosocomial environments, human skin, as well as mucosal surfaces. ${ }^{2}$ Outbreaks of A. baumannii infections have been reported in various geographic areas, ${ }^{3}$ and nosocomial transmissions have been linked to environmental contamination. ${ }^{4}$ Prolonged survival is likely a major factor for nosocomial transmission of this organism, especially in intensive care units (ICUs) ${ }^{1,5-7}$ and via health-care worker contamination. ${ }^{8}$ Carbapenem has been effective against $A$. baumannii over the past decade and has often been used as an alternative to treat otherwise multi-drug resistant A. baumannii infections, but the resistance rates against carbapenem have increased dramatically, due to its frequent application in recent years. A. baumannii has been reported to be resistant to multiple antibiotics because of its ability to acquire resistance, ${ }^{9}$ which is mediated by bacterial expression of carbapenemases, including class D $\beta$-lactamases (OXA-type carbapenemases) and class $B$ metallo- $\beta$-lactamases. It was reported worldwide that the majority of carbapenem-resistant A. baumannii isolates have at least one of the following genes: $b l a_{\text {OXA-23 }}, b l a_{\text {OXA-24, }}$ and $b l a_{\text {OXA-58 }}{ }^{10-12}$ These acquired genes and $b l a_{\mathrm{OXA}-51}$, the intrinsic gene carried by $A$. baumannii, can be upregulated by insertion sequences located upstream of these genes; ISAbal is the most commonly detected. ${ }^{13}$ The existence of the OXA-23 subtype is the most common mechanism for A. baumannii resistance to the carbapenems. ${ }^{14}$ In nosocomial infections, genotyping has an important role in distinguishing the outbreak pathogens for epidemiological classifications, and common methods for pathogen genotype classifications are enterobacterial repetitive intergenic consensus PCR (ERIC-PCR), pulsed-field gel electrophoresis (PFGE) and multi-locus sequence typing (MLST). ${ }^{15}$

${ }^{1}$ Department of Clinical Laboratory, Renji Hospital, Shanghai Jiaotong University School of Medicine, Shanghai, China and ${ }^{2}$ Department of Rheumatology, Renji Hospital, Shanghai Jiaotong University School of Medicine, Shanghai, China

3These two authors share co-first authorship and contributed equally to this work.

Correspondence: Professor C Yang, Department of Rheumatology, Renji Hospital, Shanghai Jiaotong University School of Medicine. No 145 Shandong Zhong Road, Shanghai 200001, China. 
In this study, we investigated the resistance rates and epidemiological characteristics of clinical and environmental A. baumannii bacteria isolated from a neurosurgical ICU and analyzed the mechanisms of carbapenem resistance.

\section{MATERIALS AND METHODS}

\section{Bacterial strains}

A total of 27 clinical strains were obtained from 27 individual patients of the neurosurgical ICU, Renji Hospital Shanghai, China from July to November 2012. Isolate sources included sputum (23), throat swab (1), urine (1) and drainage liquid (2). Environmental strains were isolated from 214 surface samples in the ward of neurosurgical ICU at the same period from which 28 (28/214, 13.1\%) were A. baumannii positive, including bedside tables (17), bed rails (7), the touch pads of ventilator equipment (3) and door handles (1) but not the hands of health-care workers (0). The identification of all bacteria was performed by a Microscan WalkAway 96 plus automated system (Siemens Healthcare Diagnostics, Berlin, Germany). Escherichia coli ATCC25922 and Pseudomonas aeruginosa ATCC27853 were used as reference strains. All selected isolates were stored at $-20^{\circ} \mathrm{C}$ and grown overnight on blood agar plates at $35^{\circ}$ $\mathrm{C}$ before use.

\section{Antimicrobial susceptibility testing}

The MICs of antimicrobial agents against the isolates were determined by the agar dilution method. The antimicrobial agents, including amikacin, ciprofloxacin, gentamicin, ceftazidime, cefotaxime, cefoxitin, minocycline, sulfamethoxazole, meropenem, piperacillin, tazobactam, cefepime, imipenem, cefoperazone,sulbactam, colistin and tigecycline, were purchased from the Kejia Doping Test Equipment Company (Shanghai, China). The susceptibility breakpoints were interpreted as recommended by the Clinical and Laboratory Standards Institute (CLSI, 2010) except for tigecycline. ${ }^{16}$ For tigecycline, we used breakpoints recommended by the US Food and Drug Administration.

\section{Enterobacterial repetitive intergenic consensus-PCR}

A. baumannii genomic DNA was extracted as described previously. ${ }^{17}$ The primer pair ERIC1 (5'-ATGTAAGCTCCTGGGGATTCAC-3') and ERIC2 (5'AAGTAAGTGACTGGGGTGAGCG-3') were used to amplify intervening fragments of ERIC in the genomic DNA. Amplification reactions were performed in a final volume of $25 \mu \mathrm{l}$. Each reaction system contained $2.5 \mu \mathrm{l}$ of $10 \times$ PCR buffer, $2 \mu \mathrm{l}$ dNTP mixture, $0.125 \mu \mathrm{l}$ Taq enzyme, $0.5 \mu l$ each primer $\left(10 \mu \mathrm{moll}^{-1}\right)$ and $1 \mu \mathrm{l}$ DNA template, added to $25 \mu \mathrm{l}$ of $\mathrm{ddH}_{2} \mathrm{O}$. Amplification reactions were carried out in an ABI 2700 thermal cycler (Applied Biosystems, Carlsbad, CA, USA) with initial denaturation ( $5 \mathrm{~min}$ at $94^{\circ} \mathrm{C}$ ), followed by four cycles of denaturation $\left(1 \mathrm{~min}\right.$ at $\left.94^{\circ} \mathrm{C}\right)$, annealing $\left(1 \mathrm{~min}\right.$ at $\left.26^{\circ} \mathrm{C}\right)$ and extension $\left(1 \mathrm{~min}\right.$ at $\left.72^{\circ} \mathrm{C}\right)$ and 40 cycles of denaturation $\left(30 \mathrm{~s}\right.$ at $\left.94^{\circ} \mathrm{C}\right)$, annealing $\left(30 \mathrm{~s}\right.$ at $\left.40^{\circ} \mathrm{C}\right)$ and extension $\left(1 \mathrm{~min}\right.$ at $\left.72^{\circ} \mathrm{C}\right)$, with a final extension at $72^{\circ} \mathrm{C}$ for $10 \mathrm{~min}$. Amplified products of each sample were subjected to electrophoresis in $1.2 \%$ agarose gel containing ethidium bromide.

\section{Pulsed-field gel electrophoresis}

The PFGE procedures were carried out according to a previously described method. ${ }^{18}$ Strains were digested with proteinase K (Takara Biotechnology Co. LTD., Dalian, China), and chromosomal DNA was digested with ApaI (Takara Biotechnology Co. LTD.). The PFGE was run in a CHEFMapperTM system (Bio-Rad Laboratories, Inc., Berkeley, CA, USA), with pulses ranging from 5 to $20 \mathrm{~s}$ at $14^{\circ} \mathrm{C}$ with $6 \mathrm{~V} \mathrm{~cm}^{-1}$ for $19 \mathrm{~h}$. The DNA band profiles were detected after staining with ethidium bromide and photographed with the Image Lab software (Bio-Rad). Criteria for pulsotyping were the location and the number of different fragments as described previously. ${ }^{19,20}$ The exact same profiles were considered as the same type, 1- to 3-band differences as subtypes of the same type and $>3$ different bands as another type.

\section{Multi-locus sequence typing}

MLST was performed based on analyses and comparison of internal fragment sequences from seven housekeeping genes ( $g l t A, g y r B, g d h B, r e c A, c p n 60$, gpi and $r p o D) .{ }^{21}$ Amplification reactions were carried out in an ABI 2700 thermal cycler (Applied Biosystems) with 30 cycles of denaturation $\left(30 \mathrm{~s}\right.$ at $94^{\circ} \mathrm{C}$ ), annealing $\left(30 \mathrm{~s}\right.$ at $\left.54^{\circ} \mathrm{C}\right)$ and extension $\left(1 \mathrm{~min}\right.$ at $\left.72^{\circ} \mathrm{C}\right)$ after 5 -min denaturation at $94^{\circ} \mathrm{C}$ and followed by a final extension at $72^{\circ} \mathrm{C}$ for $10 \mathrm{~min}$. All PCR products were purified and sequenced with the assistance of JIE LI BioTechnologies (Shanghai, China). The sequences of these seven housekeeping genes were analyzed by means of the PubMed database (http://pubmlst.org/ abaumannii/). The sequence type (ST) was designated according to the allelic profiles in the database. The eBURST algorithm (version 3; http://eburst.mlst. net/) was used to assign STs to clonal complexes (CCs) and to assess the genetic relationship with definition of groups sharing alleles at $\geqslant 6$ of the 7 loci. ${ }^{22}$

\section{PCR amplification of carbapenemase genes}

The genes of the molecular Ambler class B enzymes ( $\left.b l a_{\mathrm{IMP}-\text { type, }}, b l a_{\mathrm{VIM} \text {-type }}\right)$ and class D enzymes (bla $a_{\mathrm{OXA}-23-\text {-like, }} b a_{\mathrm{OXA}-24-\text { like, }} b l a_{\mathrm{OXA}-51-\text { like }}$ and $\left.b l a_{\mathrm{OXA}-58-\text {-like }}\right)$ were analyzed by PCR. PCR primers were designed using the Primer 3.0 software (Primer PREMIER, Palo Alto, CA, USA) (Table 1). Amplification reactions were carried out in a final volume of $25 \mu \mathrm{l}$ with $2.5 \mu \mathrm{l}$ of $10 \times \mathrm{PCR}$ buffer, $2 \mu \mathrm{l} \mathrm{dNTP}$ mixture, $0.125 \mu \mathrm{l}$ rTaq enzyme, $0.5 \mu \mathrm{l}$ of each primer (10 $\mu$ moll $1^{-1}$ ) and $1 \mu \mathrm{l}$ DNA template and added $\mathrm{ddH}_{2} \mathrm{O}$ in a total volume of $25 \mu \mathrm{l}$. Amplification reactions were carried out in a ABI 2700 thermal cycler (Applied Biosystems) with an initial denaturation step $\left(5 \mathrm{~min}\right.$ at $94^{\circ} \mathrm{C}$ ) followed by 30 cycles of denaturation $\left(30 \mathrm{~s}\right.$ at $\left.94^{\circ} \mathrm{C}\right)$, annealing $\left(30 \mathrm{~s}\right.$ at $\left.54-56^{\circ} \mathrm{C}\right)$ and extension $\left(45 \mathrm{~s}\right.$ at $72^{\circ} \mathrm{C}$ ) and a final extension at $72^{\circ} \mathrm{C}$ for $7 \mathrm{~min}$. Amplified products of each sample were subjected to electrophoresis in $1.2 \%$ agarose gel containing ethidium bromide. After TANON gel imaging, PCR product purification and DNA sequencing were performed by JIE LI BioTechnologies. The resulting $b a_{\mathrm{OXA}-23}$ was analyzed with the corresponding bla $a_{\mathrm{OXA}-23}$ sequence in GenBank (CP003847.1)

\section{Statistical analyses}

Statistical analyses of antimicrobial susceptibility results were carried out by the WHONET5.4 software provided by the World Health Organization. Resistance rates for each antibiotic drug were compared between clinical $A$. baumannii and environmental A. baumannii, by Chi-square or Fisher's exact test. $P$-values $<0.05$ were considered as significant.

\section{RESULTS}

\section{Antimicrobial susceptibility testing}

In the present study, a total of $55 \mathrm{~A}$. baumannii isolates, including 27 clinical isolates and 28 environmental isolates, were selected from the neurosurgical ICU of our hospital. The resistance characteristics of these isolates are summarized in Table 2. All isolates were susceptible to colistin and tigecycline. Among 27 clinical isolates, all (100\%) were resistant to trimethoprim-sulfamethoxazole, and $>80 \%$ were resistant

\section{Table 1 Sequences of primers designed for this study}

\begin{tabular}{|c|c|c|}
\hline Primer & Sequence & Product length \\
\hline \multirow[t]{2}{*}{ blaoxA-23-like } & P1 5'-GCTCTAAGCCGCGCAAATAC-3' & $123 \mathrm{bp}$ \\
\hline & P2 5'-GACCTTTTCTCGCCCTTCCA-3' & \\
\hline \multirow[t]{2}{*}{ bla OXA-24-like } & P1 5'-ACGGACTGGCCTAGAGCTAA-3' & 262 bp \\
\hline & P2 5'-AACACCCATTCCCCATCCAC-3' & \\
\hline \multirow[t]{2}{*}{ blaoxA-51-like } & P1 5'-AACGCTTCCATTTAGCCCAA-3' & 152 bp \\
\hline & P2 5'-GAGGCTGAACAACCCATCCA-3' & \\
\hline \multirow[t]{2}{*}{ blaoxA-58-like } & P1 5'-GGTCTACAGCCATTCCCCAG-3' & 483 bp \\
\hline & P2 5'-ATGGCACGCATTTAGACCGA-3' & \\
\hline \multirow[t]{2}{*}{ blavim-1-like } & P1 5'-GAAGGACTCTCATCGAGCGG-3' & $310 b p$ \\
\hline & P2 5'-GTGCTTTGACAACGTTCGCT-3' & \\
\hline \multirow[t]{2}{*}{ blavım-2-like } & P1 5'-TCCACGCACTTTCATGACGA-3' & $285 b p$ \\
\hline & P2 5'-AGACGTGCGTGACAACTCAT-3' & \\
\hline \multirow[t]{2}{*}{ bla|MP-1-like } & P1 5'-CACTTGGTTTGTGGAGCGTG-3' & 263 bp \\
\hline & P2 5'-GTCCCGGGCCTGGATAAAAA-3' & \\
\hline
\end{tabular}


Table 2 Susceptibility analysis of Acinetobacter baumannii in this study

\begin{tabular}{|c|c|c|c|c|c|c|}
\hline \multirow{2}{*}{ Antimicrobial agents } & \multicolumn{2}{|c|}{ Clinical isolates $(\mathrm{n}=27)$} & \multicolumn{2}{|c|}{ Environmental isolates $(\mathrm{n}=28)$} & \multirow{2}{*}{$x^{2}$} & \multirow{2}{*}{$\mathrm{P}$} \\
\hline & $\operatorname{MIC90}\left(\mathrm{mgl}^{-1}\right)$ & $R \%$ & $\operatorname{MIC90}\left(\mathrm{mgl}^{-1}\right)$ & $R \%$ & & \\
\hline Piperacillin & $>256$ & 85.2 & 256 & 28.6 & 65.32 & $<0.01$ \\
\hline Piperacillin/Tazobactam & 256 & 81.5 & 32 & 10.7 & 100.87 & $<0.01$ \\
\hline Ceftazidime & 128 & 88.9 & 128 & 28.6 & 75.02 & $<0.01$ \\
\hline Cefotaxime & 256 & 81.5 & 128 & 21.4 & 72.30 & $<0.01$ \\
\hline Cefepime & 128 & 85.2 & 32 & 14.3 & 100.54 & $<0.01$ \\
\hline Cefoxitin & $>256$ & 100 & 256 & 92.9 & 5.43 & $<0.05$ \\
\hline Imipenem & 32 & 59.3 & 1 & 7.1 & 61.43 & $<0.01$ \\
\hline Meropenem & 64 & 74.1 & 1 & 3.6 & 104.61 & $<0.01$ \\
\hline Amikacin & $>256$ & 70.4 & $>256$ & 28.6 & 34.95 & $<0.01$ \\
\hline Gentamicin & $>256$ & 85.2 & $>256$ & 35.7 & 51.24 & $<0.01$ \\
\hline Ciprofloxacin & $>256$ & 85.2 & 256 & 32.1 & 58.13 & $<0.01$ \\
\hline Trimethoprim-sulfamethoxazole & $>256$ & 100 & $>256$ & 50 & 66.67 & $<0.05$ \\
\hline Cefoperazone-sulbactam & 32 & 51.9 & 0.5 & 3.6 & 16.15 & $<0.01$ \\
\hline Minocycline & 16 & 25.9 & 8 & 10.7 & 7.73 & $<0.01$ \\
\hline Tigecycline & 2 & 0 & 0.5 & 0 & & \\
\hline Colistin & 0.5 & 0 & 0.25 & 0 & & \\
\hline
\end{tabular}

Abbreviations: MIC90, MIC for $90 \%$ of the organisms; R \%, percent resistant.

to cephalosporins (ceftazidime, cefotaxime, cefepime and cefoxitin), ciprofloxacin and gentamicin. The majority of A. baumannii strains were carbapenem resistant (CRAB), with 59.3\% against imipenem and $74.1 \%$ against meropenem. Minocycline had the lowest resistance rate of $25.9 \%$. In contrast, environmental isolates were more susceptible to all antimicrobial agents mentioned above, compared with clinical isolates. The resistance rates against imipenem, meropenem, cefoperazone-sulbactam and minocycline were 7.1, 3.6, 3.6 and $10.7 \%$ respectively, whereas resistance rates were $20-50 \%$ against other antimicrobial agents, except for cefoxitin (92.9\%). Statistical analysis of resistance rates against each antibiotic drug revealed significant differences between clinical and environmental isolates $(P<0.05)$.

\section{Molecular typing}

Molecular typing is by PFGE, ERIC-PCR and MLST.

\section{Pulsed-field gel electrophoresis}

Molecular typing by PFGE identified four major clinical groups (A, B, $\mathrm{D}, \mathrm{E})$ and nine major environmental groups, which were termed A-I. Twenty-three clinical isolates were classified in PFGE group A, only one isolate was clustered in PFGE group B, two isolates were in PFGE group $\mathrm{D}$ and one isolate in group $\mathrm{E}$. The 28 environmental isolates showed more diverse genetic types than the clinical isolates, but 15 isolates were also PFGE type $\mathrm{A}$, which was the major fraction (Table 3).

\section{Enterobacterial repetitive intergenic consensus PCR}

With ERIC-PCR analyses, the 27 clinical A. baumannii isolates were classified into three major groups $\mathrm{a}(20), \mathrm{b}(6)$ and $\mathrm{c}(1)$, whereas environmental isolates yielded six groups $(\mathrm{a}-\mathrm{f})$. Fourteen environment strains showed identical DNA fingerprinting pattern as type a strains, four isolates were type $b$, two isolates were type $c$ and others were different in the size of $>3$ bands and were designated as type $d(4)$, e (2) and $f(2)$ (Table 3 ). The grouping of ERIC-PCR results did correlate only partly with the PFGE clustering.

\section{Multi-locus sequence typing}

According to the MLST results, 27 clinical A. baumannii isolates were grouped into five existing STs (ST208, 1-3-3-2-2-97-3; ST368, 1-3-32-2-140-3; ST191, 1-3-3-2-2-94-3; ST195, 1-3-3-2-2-96-3; ST540, 1-3$3-2-2-160-3$ ) and four non-clonal STs (Table 3). ST208, accounting for $66.7 \%(18 / 27)$, was the major clone that spread in the neurosurgical ICU of our hospital, followed by ST540 (2/27, 7.4\%) and one each of ST368, ST191 and ST195. Clonal relation analysis showed that ST208, ST368, ST191, ST195 and ST540 belonged to the CC92 lineage, with only one locus (gpi) different among these STs, accounting for $85.2 \%(24 / 27)$ of all clinical isolates. Furthermore, the MLST results of the clinical isolates showed that CC92 corresponded to the group A obtained by PFGE. Molecular typing of environmental isolates by MLST identified two existing STs, ST208 and ST229, with nine and four isolates respectively, but a significant proportion (54\%) had to be assigned as non-clonal STs (Figure 1).

\section{PCR amplification for carbapenemase genes}

The two groups of strains were analyzed for their carbapenem resistance genes. bla $a_{\mathrm{OXA}-51}$ is intrinsically found in A. baumannii and was detected in all strains. Twenty-one of the 27 clinical isolates carried $b a_{\text {OXA-23 }}$, whereas only 3 of the 28 environmental isolates were $b l a_{\text {OXA-23 }}$ positive. From the 27 clinical isolates, 20 were carbapenem non-susceptible A. baumannii (CNSAb) and 7 were carbapenemsusceptible A. baumannii strains. All of the clinical CNSAb, as well as 1 $\mathrm{CNSAb}$ strain, carried the bla $a_{\mathrm{OXA}-23}$ gene. In addition, two of the three environmental CNSAb, as well as one CNSAb strain, were OXA-23 positive. However, there were no $b l a_{\mathrm{IMP}-\mathrm{type}}, b l a_{\mathrm{VIM}-\mathrm{type}}, b l a_{\mathrm{OXA}-24-\text { like }}$ and $b l a_{\mathrm{OXA}-58-\text { like }}$ genes among the isolates.

\section{DISCUSSION}

In recent years, A. baumannii has emerged as a successful pathogen of various troublesome nosocomial infections, with the ability to resist various kinds of antibiotics. ${ }^{23}$ As observed in other Asian countries, ${ }^{24}$ our study revealed that these strains were resistant to various kinds of antimicrobial agents, as a result of carbapenemase expression levels, mainly including class B metallo- $\beta$-lactamases and class D OXA-type 
Table 3 Molecular typing results of clinical and environmental Acinetobacter baumannii strains and the distribution of OXA-23 enzymes

\begin{tabular}{|c|c|c|c|c|c|c|c|}
\hline \multirow{2}{*}{$\frac{\text { No. of strains }}{\text { Clinical strains }}$} & \multirow[t]{2}{*}{ PFGE } & \multirow[t]{2}{*}{ ERIC-PCR (No.) } & \multirow[t]{2}{*}{ MLST (No.) } & \multicolumn{2}{|c|}{$\begin{array}{c}\text { No. of CSAb } \\
\text { OXA-23(+)OXA-23(-) }\end{array}$} & \multicolumn{2}{|c|}{$\begin{array}{c}\text { No. of CRAB } \\
\text { OXA-23(+)OXA-23(-) }\end{array}$} \\
\hline & & & & & & & \\
\hline 1 & B & $a(1)$ & ND (1) & 0 & 0 & 1 & 0 \\
\hline 2 & $\mathrm{D}$ & $a(2)$ & $\begin{array}{l}\text { ST208 (1) } \\
\text { ND (1) }\end{array}$ & 0 & 0 & 2 & 0 \\
\hline 1 & $\mathrm{E}$ & $a(1)$ & ND (1) & 0 & 0 & 1 & 0 \\
\hline \multicolumn{8}{|c|}{ Environmental strains } \\
\hline 1 & $\mathrm{C}$ & $c(1)$ & ND (1) & 0 & 1 & 0 & 0 \\
\hline 2 & $\mathrm{D}$ & $\begin{array}{l}a(1) \\
d(1)\end{array}$ & $\begin{array}{l}\text { ST229 (1) } \\
\text { ND (1) }\end{array}$ & 0 & 2 & 0 & 0 \\
\hline 3 & $\mathrm{E}$ & $\begin{array}{l}b(2) \\
d(1)\end{array}$ & ND (3) & 0 & 3 & 0 & 0 \\
\hline 2 & $\mathrm{~F}$ & $\begin{array}{l}a(1) \\
d(1)\end{array}$ & ND (3) & 0 & 2 & 0 & 0 \\
\hline 1 & G & $\mathrm{b}(1)$ & ND (1) & 0 & 1 & 0 & 0 \\
\hline 1 & $\mathrm{H}$ & $d(1)$ & ND (1) & 0 & 1 & 0 & 0 \\
\hline 1 & 1 & $c(1)$ & ND (1) & 0 & 1 & 0 & 0 \\
\hline
\end{tabular}

Abbreviations: CRAB, carbapenem resistant; CSAb, carbapenem-susceptible A. baumannii; ERIC-PCR, enterobacterial repetitive intergenic consensus PCR; MLST, multi-locus sequence typing; ND, not determined; PFGE, pulsed-field gel electrophoresis.

carbapenemases. ${ }^{25}$ Colistin and tigecycline were the main choices for the treatment of infection caused by CRAB. Although colistin-resistant strains have been discovered in some area, our survey showed that colistin retained its activity against these $\mathrm{CRAB}$ isolates carrying $b l a_{\text {OXA-23 }}$ have been discovered worldwide and are prevalent in Asian regions. ${ }^{16,22,26-28}$ Our study indicated that $b a_{\text {OXA-23 }}$ was the most prevalent CHDL (carbapenem hydrolyzing class D $\beta$-lactamase) gene and was most frequently found in CRAB isolates collected in our neurosurgical ICU. Many study indicated that the dissemination of bla $a_{\mathrm{OXA}-23}$ is attributed to transposons, including Tn2006, Tn2007 and Tn2008, while clonal spread had a minor role. ${ }^{29}$ Tn2008 was recognized as the major transposon carrying $b a_{\mathrm{OXA}-23}$ in China. ${ }^{30}$ However, the spread of $b l a_{\text {OXA-23 }}$ in our hospital need to be validated.

In our study, $13.1 \%$ of the 214 environmental samples collected in our neurosurgical ICU were A. baumannii positive, which was higher compared with previous reports in which the environmental surfaces surrounding patients in ICUs were $2.3 \%$ (513 samples), $7.3 \%$ (151 samples) and $9.8 \%$ (479 samples) A. baumannii positive. ${ }^{4,31,32}$ The sites commonly contaminated in our ward were bedside tables frequently touched by both the health-care workers and patients.

PFGE has been considered as the standard for typing of many bacterial species owing to its superior reproducibility and high discriminatory power ${ }^{33}$ and has been carried out for typing of organisms in local epidemiological studies, such as A. baumannii, ${ }^{34,35}$ Escherichia coli ${ }^{20}$ and Klebsiella pneumoniae. ${ }^{36}$ PFGE can be used for investigating bacterial relations after clinical outbreaks by generating distinct patterns of restricted chromosomal DNA fragments. According to our study, the clinical isolates had more clone types than the environmental isolates, with group A being the most prominent type.

ERIC-PCR uses amplification of intervening fragments between highly conserved ERIC sequences by means of consensus primers. ${ }^{37}$ ERIC-PCR is a rapid, simple and low-cost method for molecular typing, which has been applied previously for clinical A. baumannii isolate differentiation. Our ERIC-PCR results showed that clone a is the common genotype with $74.1 \%$ in clinical strains (20/27) and $50 \%$ in environmental isolates (14/28). The vast majority of the PFGE A strain also appeared as a common a strain in ERIC-PCR classifications (clinical samples 23A vs 16a and environmental samples $15 \mathrm{~A}$ vs $12 \mathrm{a}$ ), while other classifications did not match well.

MLST, based on analyses of nucleotide sequences from internal fragments of multiple housekeeping genes, has been considered as an unambiguous typing method for global and long-term epidemiological studies. ${ }^{18}$ Our MLST results, based on comparative sequence analyses of conserved regions in 7 housekeeping genes of the 27 clinical A. baumannii isolates, led to the clonal ST208, ST368, ST191, ST195 and ST540 groups and 4 non-clonal STs. ST208 (18/27, 66.7\%) was the major clone that spread in the neurosurgical ICU infections of our hospital, followed by ST540 (2/27, 7.4\%). Clonal relation analysis showed that ST208, ST368, ST191, ST195 and ST540 belonged to CC92 with only one locus (gpi) difference among these STs, accounting for $85.2 \%(24 / 27)$ and reflecting the global predominance of the CC92 A. baumannii type. ${ }^{16}$ Fifteen environmental isolates of PFGE group A were assigned to ST208 (9/28, 32.1\%), ST229 (3/28, 

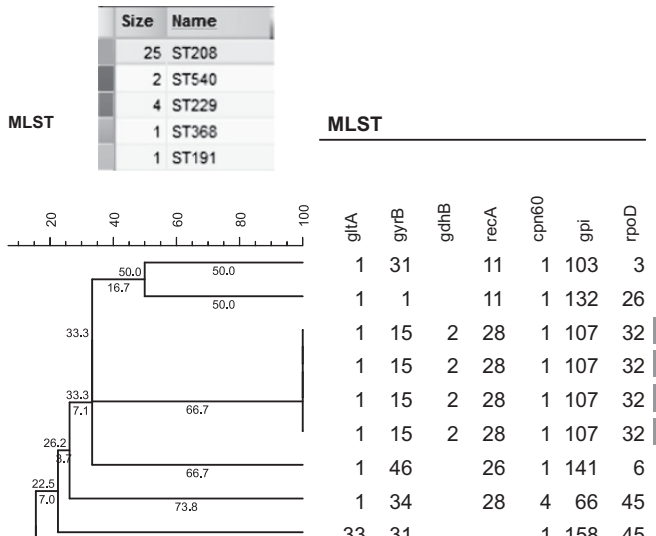

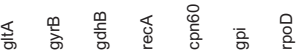

$\begin{array}{llllll}1 & 31 & 11 & 1 & 103 & 3\end{array}$

$\begin{array}{llllll}1 & 1 & 11 & 1 & 132 & 26\end{array}$

$\begin{array}{lllllll}1 & 15 & 2 & 28 & 1 & 107 & 32\end{array}$

$\begin{array}{lllllll}1 & 15 & 2 & 28 & 1 & 107 & 32\end{array}$

$\begin{array}{lllllll}1 & 15 & 2 & 28 & 1 & 107 & 32\end{array}$

$\begin{array}{lllllll}1 & 15 & 2 & 28 & 1 & 107 & 32\end{array}$

$\begin{array}{lllllll}1 & 46 & 26 & 1 & 141 & 6\end{array}$

$\begin{array}{llllll}1 & 34 & 28 & 4 & 66 & 45\end{array}$

$\begin{array}{lllll}33 & 31 & 1 & 158 & 45\end{array}$

$\begin{array}{lllllll}1 & 3 & 3 & 7 & 2 & 97 & 3\end{array}$

$\begin{array}{lllllll}1 & 3 & 3 & 28 & 2 & 97 & 3\end{array}$

$\begin{array}{llllll}1 & 3 & 3 & 2 & 2 & 160\end{array}$

$\begin{array}{lllllll}1 & 3 & 3 & 2 & 2 & 160 & 3\end{array}$

$\begin{array}{llllll}1 & 3 & 3 & 2 & 2 & 97\end{array}$

$\begin{array}{llllll}1 & 3 & 3 & 2 & 2 & 97\end{array}$

$\begin{array}{lllllll}1 & 3 & 3 & 2 & 2 & 97 & 3\end{array}$

$\begin{array}{llllll}1 & 3 & 3 & 2 & 2 & 97\end{array}$

$\begin{array}{lllllll}1 & 3 & 3 & 2 & 2 & 97 & 3\end{array}$

$\begin{array}{lllllll}1 & 3 & 3 & 2 & 2 & 97 & 3\end{array}$

$\begin{array}{lllllll}1 & 3 & 3 & 2 & 2 & 97 & 3\end{array}$

$\begin{array}{llllll}1 & 3 & 3 & 2 & 2 & 97\end{array}$

$\begin{array}{lllllll}1 & 3 & 3 & 2 & 2 & 97 & 3 \\ 1 & 3 & 3 & 2 & 2 & 97 & 3\end{array}$
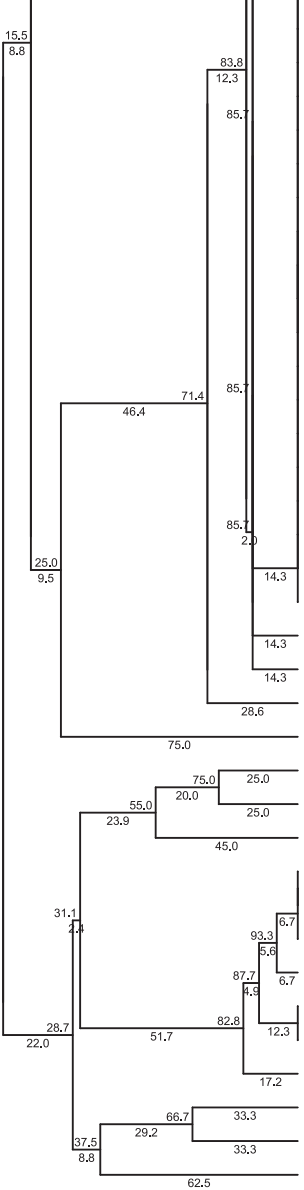

1

1

$\begin{array}{lllll}3 & 2 & 2 & 97\end{array}$

1

$\begin{array}{llllll}1 & 3 & 3 & 2 & 2 & 97\end{array}$

$\begin{array}{llllll}1 & 3 & 3 & 2 & 2 & 97\end{array}$

$\begin{array}{lllllll}1 & 3 & 3 & 2 & 2 & 97\end{array}$

$\begin{array}{llllll}1 & 3 & 3 & 2 & 2 & 97\end{array}$

$\begin{array}{llllll}1 & 3 & 3 & 2 & 2 & 97\end{array}$

$\begin{array}{llllll}1 & 3 & 3 & 2 & 2 & 97\end{array}$

$\begin{array}{lllll}3 & 3 & 2 & 2 & 97\end{array}$

$\begin{array}{llllll}1 & 3 & 3 & 2 & 2 & 97\end{array}$

$\begin{array}{llllll}1 & 3 & 3 & 2 & 2 & 97\end{array}$

$\begin{array}{llllll}1 & 3 & 3 & 2 & 2 & 97\end{array}$

$\begin{array}{llllll}1 & 3 & 3 & 2 & 2 & 97\end{array}$

$\begin{array}{llllll}1 & 3 & 3 & 2 & 2 & 97\end{array}$

$\begin{array}{llllll}3 & 3 & 2 & 2 & 97 & 3\end{array}$

$\begin{array}{llllll}1 & 3 & 3 & 2 & 2 & 140\end{array}$

$\begin{array}{rrrrrrr}1 & 3 & 3 & 2 & 2 & 94 & 3\end{array}$

$\begin{array}{lllllll}1 & 3 & 3 & 52 & 2 & 96 & 3\end{array}$

$\begin{array}{llll}12 & 2 & 110 \quad 26\end{array}$

52

$\begin{array}{rr}52 & \\ 52 & 46 \\ 9 & \end{array}$

5280

52

52

5293

52

$52 \quad 46$

5246

47

47

30

$\begin{array}{lll}6 & 96 & 65\end{array}$

$\begin{array}{llll}52 & 6 & 97 & 65\end{array}$

$\begin{array}{llll}7 & 6 & 97 & 65\end{array}$

$\begin{array}{llll}7 & 39 & 97 & 11\end{array}$

7

$\begin{array}{llll}7 & 39 & 97 & 11\end{array}$

$\begin{array}{llll}7 & 39 & & 11 \\ 7 & & 141 & 11\end{array}$

$\begin{array}{llll}7 & & 141 & 11 \\ 7 & 39 & 11\end{array}$

$\begin{array}{llll}7 & 39 & 103 & 11\end{array}$

$\begin{array}{lll}7 & 39 & 10\end{array}$

$\begin{array}{lll}39 & 97 & 65\end{array}$

$\begin{array}{llll}52 & 39 & 97 & 56\end{array}$

E15

E27

ST229 E8

ST229 E9

ST229 E11

ST229 E12

E10

E20

E23

$\mathrm{C} 22$

$\mathrm{C} 23$

ST540 C25

ST540 C27

ST208 E1

ST208 E2

ST208 E3

ST208 E5

ST208 E7

ST208 E24

ST208 E25

ST208 C1

ST208 C2

ST208 C3

ST208 C4

ST208 C5

ST208 C6

ST208 C9

ST208 C10

ST208 C11

ST208 C11

ST208 C12

ST208 C14

ST208 C15

ST208 C16

ST208 C17

ST208 C19

ST208 C20

ST208 C24

ST208 C26

ST368 C7

ST191 C8

C21

C13

E21

$$
\text { E26 }
$$

$$
\text { E6 }
$$$$
\text { E4 }
$$

$$
\text { E13 }
$$$$
\text { E22 }
$$$$
\text { E18 }
$$

$$
\text { E14 }
$$

$$
\text { E19 }
$$$$
\text { E16 }
$$

E17

C18

E28

Figure 1 Phylogenetic tree of MLST. A full color version of this figure is available at The Journal of Antibiotics journal online.
$10.7 \%)$ and a distinct allele profile $(3 / 28,10.7 \%)$. Based on all of the above data, a large proportion of the environmental isolates (53\%) and four clinical isolates $(14.8 \%)$ in this study were assigned to non-clonal STs. As expected, most of the non-clonal STs were found to be susceptible isolates and most OXA-23(+) clinical strains belonged to CC92. ${ }^{38}$

Genotype analysis were carried out by molecular typing (ERICPCR, PFGE, MLST), and we found that there was a certain similarity between clinical and environmental isolates, but a general clonal transmission as a result of environmental contamination could not be identified, probably because of the significant differences in antimicrobial susceptibilities. However, the identification of environmental contamination suggested a potential risk for nosocomial transmission, but in this study we analyzed only a limited number of samples from both patients and the environment, hence, further research is necessary.

In summary, colistin and tigecycline can be the last treatment option for CRAB. However, its efficacy, toxicity and resistance are further concerns. Patients' isolates were genetically similar to environmental isolates, with a major clone corresponding to CC92. The clonal spread of isolates producing $b a_{\mathrm{OXA}-23}$ carbapenemase might be the major factor that resulted in the high carbapenem resistance rate of A. baumannii infections in our neurosurgical ICU, yet this was not due to a high rate of resistant environmental isolates.

\section{CONFLICT OF INTEREST}

The authors declare no conflict of interest.

\section{ACKNOWLEDGEMENTS}

This study was supported by National Natural Science Foundation of China. (Grant 81371874). We thank Professor Hongsheng Zhu for a critical reading and revision of the manuscript and Demei Zhu and Fupin Hu for the technical support.

1 Abbott, I., Cerqueira, G. M., Bhuiyan, S. \& Peleg, A. Y. Carbapenem resistance in Acinetobacter baumannii: laboratory challenges, mechanistic insights and therapeutic strategies. Expert Rev. Anti Infect. Ther. 11, 395-409 (2013).

2 Chen, Z. et al. Molecular epidemiology of carbapenem-resistant Acinetobacterspp. from XiangYa Hospital, in Hunan Province, China. J. Basic Microbiol. 53, 121-127 (2003).

3 Levin, A. S., Gobara, S., Mendes, C. M. F., Cursino, M. R. \& Sinto, S. Environmental contamination by multidrug-resistant Acinetobacter baumannii in an intensive care unit. Infect. Control Hosp. Epidemiol. 22, 717-720 (2001).

4 Dai, X. T. et al. The epidemiology and resistance mechanisms of Acinetobacter baumannii isolates from the respiratory department ICU of a hospital in China. Microb. Drug Resist. 20, 618-622 (2014).

5 Chang, K. M. et al. Suitable restriction enzyme for standardization of pulsed-field gel electrophoresis protocol and interlaboratory comparison of Acinetobacter baumannii. J. Microbiol. Immunol. Infect. 46, 195-201 (2013).

6 Cristina, M. L., Spagnolo, A. M. \& Cenderello, N. Multidrug-resistant Acinetobacter baumannii outbreak: an investigation of the possible routes of transmission. Public Health 127, 386-391 (2013).

7 Diancourt, L., Passet, V., Nemec, A., Dijkshoorn, L. \& Brisse, S. The population structure of Acinetobacter baumannii: expanding multiresistant clones from an ancestral susceptible genetic pool. PLOS ONE 5, e10034 (2010).

$8 \mathrm{CLSI}$. Performance standards for antimicrobial susceptibility testing. Twenty-third Informational Supplement M100-S23 Committee for Clinical Laboratory Standards Institute (CLSI, Wayne, PA, USA, 2013).

9 Brown, S. \& Amyes, S. OXA (beta)-lactamases in Acinetobacter: the story so far. J. Antimicrob. Chemother. 57, 1-3 (2006).

10 Peleg, A. Y., Seifert, H. \& Paterson, D. L. Acinetobacter baumannii: emergence of a successfulpathogen. Clin. Microbiol. Rev. 21, 538-582 (2008).

11 Srinivasan, V. B., Rajamohan, G., Pancholi, P., Stevenson, K., Tadesse, D. \& Patchanee, P. Genetic relatedness and molecular characterization of multidrug resistant Acinetobacter baumannii isolated in central Ohio, USA. Ann. Clin. Microbiol. Antimicrob. 8, 21 (2009).

12 Zarrilli, R. et al. A plasmid-borne blaOXA-58 gene confers imipenem resistance to Acinetobacter baumanniilsolates from a Lebanese Hospital. Antimicrob. Agents Chemother. 52, 4115-4120 (2008). 
13 Kempf, M. \& Rolain, J. M. Emergence of resistance to carbapenems in Acinetobacter baumannii in Europe: clinical impact and therapeutic options. Int. J. Antimicrob. Agents 39, 105-114 (2012).

14 Adams-Haduch, J. M. et al. Genetic basis of multidrug resistance in Acinetobacter baumannii clinical isolates at a tertiary medical center in Pennsylvania. Antimicrob. Agents Chemother. 52, 3837-3843 (2008).

15 Pendleton, J. N., Gorman, S. P. \& Gilmore, B. F. Clinical relevance of the ESKAPE pathogens. Expert Rev. Anti Infect. Ther. 11, 297-308 (2013).

16 de Oliveira, A. C. \& Damasceno, Q. S. Surfaces of the hospital environment as possible deposits of resistant bacteria: a review. Rev. EsC. Enferm. USP. 44, 1118-1123 (2010).

$17 \mathrm{Fu}$, Y., Zhou, J \& Zhou, H. Wide dissemination of OXA-23-producing carbapenemresistant Acinetobacter baumannii clonal complex 22 in multiple cities of China. J. Antimicrob. Chemother. 65, 644-650 (2010).

18 Durmaz, R., Otlu, B. \& Koksal, F. The optimization of a rapid pulsed-field gel electrophoresis protocol for the typing of Acinetobacter baumannii, Escherichia coli and Klebsiella spp. Jpn. J. Infect. Dis. 62, 372-377 (2009).

19 Hamouda, A. Evans, B. A. Towner, K. J. \& Amyes, S. G. Characterization of epidemiologically unrelated Acinetobacter baumannii isolates from four continents by use of multilocus sequence typing, pulsed-field gel electrophoresis, and sequencebased typing of bla(OXA-51-like) genes. J. Clin. Microbiol. 48, 2476-2483 (2010).

20 Tenover, F. C., Arbeit, R. D. \& Goering, R. V. Interpreting chromosomal DNA restriction patterns produced by pulsed-field gel electrophoresis: criteria for bacterial strain typing. J. Clin. Microbiol. 33, 2233-2239 (1995).

21 Karah, N., Sundsfjord, A., Towner, K. \& Samuelsen, 0. Insights into the global molecular epidemiology of carbapenem non-susceptible clones of Acinetobacter baumannii. Drug Resist. Updat. 15, 237-247 (2012).

22 Lee, C. M., Liao, C. H. \& Lee, W. S. Outbreak of Klebsiella pneumoniae carbapenemase-2-producing K. pneumoniae sequence type 11 in Taiwan in 2011. Antimicrob. Agents Chemother. 56, 5016-5022 (2012).

23 Munoz-Price, L. S. \& Weinstein, R. A. Acinetobacter infection. N. Engl. J. Med. 358, 1271-1281 (2008).

24 Jean, S. S. \& Hsueh, P. R. High burden of antimicrobial resistance in Asia. Int. J. Antimicrob. Agents 37, 291-295 (2011).

25 Villegas, M. V. \& Hartstein, A. I. Acinetobacter outbreaks, 1977-2000. Infect. Control Hosp. Epidemiol. 24, 284-295 (2003).

26 Poirel, L. \& Nordmann, P. Carbapenem resistance in Acinetobacter baumannii: mechanisms and epidemiology. Clin. Microbiol. Infect. 12, 826-836 (2006).
27 Koh, T. H., Sng, L. H., Wang, G. C. Y., Hsu, L. Y. \& Zhao, Y. IMP-4 and OXA betalactamases in Acinetobacter baumannii from Singapore. J. Antimicrob. Chemother. 59, 627-632 (2007).

28 Mendes, R. E., Bell, J. M., Turnidge, J. D., Castanheira, M. \& Jones, R. N. Emergence and widespread dissemination of OXA-23, -24/40 and -58 carbapenemases among Acinetobacter spp. in Asia- Pacific nations: report from the SENTRY Surveillance Program. J. Antimicrob. Chemother. 63, 55-59 (2009).

29 M.-H., Lee., T.-L., Chen \& Lee, Y.-T. Dissemination of multidrug-resistant Acinetobacter baumannii carrying BlaOxA-23 from hospitals in central Taiwan. J. Microbiol. Immunol. Infect. 46, 419-424 (2013).

30 Wang, X., Zong, Z. \& Lu, X. Tn2008 is a major vehicle carrying bla(OXA-23) in Acinetobacter baumannii from China. Diagn. Microbiol. Infect. Dis. 69, 218-222 (2011)

31 Mezzatesta, M. L., D'Andrea, M. M. \& Migliavacca, R. Epidemiological characterization and distribution of carbapenem-resistant Acinetobacter baumannii clinical isolates in Italy. Clin. Microbiol. Infect. 18, 160-166 (2012).

32 Morgan, D. J., Liang, S. Y. \& Smith, C. L. Frequent multidrug-resistant Acinetobacter baumannii contamination of gloves, gowns, and hands of healthcare workers. Infect. Control Hosp. Epidemiol. 31, 716-721 (2010).

33 Durante-Mangoni, E. \& Zarrilli, R. Global spread of drug-resistant Acinetobacter baumannii: molecular epidemiology and management of antimicrobial resistance. Future Microbiol. 6, 407-422 (2011).

34 Singh, A., Goering, R. V., Simjee, S., Foley, S. L. \& Zervos, M. J. Application of molecular techniques to the study of hospital infection. Clin. Microbiol. Rev. 19, 512-530 (2006)

35 Tan, R., Liu, J. \& Li, M. Epidemiology and antimicrobial resistance among commonly encountered bacteria associated with infections and colonization in intensive care units in a university-affiliated hospital in Shanghai. J. Microbiol. Immunol. Infect. 47, 87-94 (2014).

36 Thom, K. A., Johnson, J. K., Lee, M. S. \& Harris, A. D. Environmental contamination because of multidrug-resistant Acinetobacter baumannii surrounding colonized or infected patients. Am. J. Infect. Contro/ 39, 711-715 (2011).

37 Dijkshoorn, L., Nemec, A. \& Seifert, H. An increasing threat in hospitals: multidrugresistant Acinetobacter baumannii. Nat. Rev. Microbiol. 5, 939-951 (2007).

38 Wang, X., Qiao, F., Yu, R., Gao, Y. \& Zong, Z. Clonal diversity of Acinetobacter baumannii clinical isolates revealed by a snapshot study. BMC Microbiol. 13, 234 (2013). 